\title{
Otimização dos custos de energia elétrica na programação da captação, armazenamento e distribuição de água
}

\author{
Edilaine Martins Soler ${ }^{\mathrm{a} *}$, Franklina Maria Bragion de Toledo ${ }^{\mathrm{b}}$, Maristela Oliveira dos Santos ${ }^{\mathrm{b}}$, \\ Marcos Nereu Arenales ${ }^{b}$ \\ aniversidade Estadual Paulista, Bauru, SP, Brasil \\ bUniversidade de São Paulo, São Carlos, SP, Brasil \\ *edilaine@fc.unesp.br
}

\begin{abstract}
Resumo
0 problema abordado neste trabalho consiste na redução dos custos de energia elétrica necessária para o funcionamento de bombas hidráulicas, que são utilizadas para captar água de poços artesianos ou estações de tratamento de água para abastecer reservatórios distribuídos por bairros de uma cidade. A população é então atendida por força gravitacional. Como o custo da energia elétrica varia ao longo do dia, é necessário um planejamento do funcionamento das bombas. 0 problema consiste em decidir quando as bombas devem permanecer ligadas e quando deve haver transferência de água entre os reservatórios para que a demanda de cada reservatório seja atendida, minimizando os custos com energia elétrica. Este problema é modelado como um problema de programação linear inteira, e uma solução heurística é proposta. Experimentos computacionais mostram a eficiência da heurística e como a abordagem pode ser utilizada para analisar o impacto de alterações na infraestrutura do sistema de abastecimento.
\end{abstract}

Palavras-chave

Abastecimento de água. Planejamento. Energia elétrica. Programação inteira mista. Heurística.

\section{Introdução}

Os sistemas de abastecimento de água têm a função de levar água em quantidade e qualidade adequadas à população para que suas necessidades sejam atendidas. No Brasil, as obras de saneamento, especialmente de sistemas de abastecimento de água às populações urbanas, foram intensificadas nas décadas de 70 e 80 , buscando atender à demanda decorrente do crescimento populacional urbano e da industrialização. Segundo resultados da última Pesquisa Nacional de Saneamento Básico realizada em 2008, pelo IBGE (Instituto Brasileiro de Geografia e Estatística), a quase totalidade dos municípios brasileiros tinha serviço de abastecimento de água em pelo menos um distrito (99,4\%). Dos 5.564 municípios existentes no país, em 2008, apenas 33 não dispunham de rede geral de distribuição (Instituto Brasileiro de Geografia e Estatística, 2011).
Ormsbee \& Lansey (1994) destacam que, devido à urbanização, estes sistemas foram se tornando mais complexos e que, tanto as agências reguladoras quanto o consumidor, exercem pressão para que o sistema opere de forma eficiente e com baixos custos operacionais. Os autores apontam que o custo de energia elétrica associado ao bombeamento de água é responsável por parte significativa do custo total do sistema e que o controle ótimo do sistema é uma ferramenta importante para minimizar seus custos operacionais. Segundo Tsutiya (2006), as despesas com energia elétrica nas empresas de saneamento básico entre 1993 e 1996 variaram entre 4,8\% e $36,3 \%$ nos diversos estados brasileiros e são o segundo ou terceiro item mais importante no orçamento das despesas de exploração. Assim, é muito relevante que as empresas de saneamento possam diminuir 
seus gastos com energia elétrica, sem prejuízo no abastecimento.

Um sistema de controle de bombeamento de água, segundo Ormsbee \& Lansey (1994), pode ser dividido em três componentes: i) um modelo hidráulico da rede; ii) um modelo de previsão de demanda; e iii) um modelo de controle ótimo. Para uma revisão destes modelos sugerimos Ormsbee \& Lansey (1994).

Um modelo de controle ótimo visa a minimização dos custos envolvidos na operação do sistema de captação e distribuição de água. Os custos envolvidos podem ser de acionamento das bombas de captação e distribuição. Desta forma, este tipo de modelo visa atender à demanda de água, respeitando as restrições do sistema, por exemplo, o volume de água nos reservatórios. Na literatura, várias técnicas foram aplicadas para obter soluções para este tipo de problema, tais como: Otimização linear (Little \& McCrodden, 1989; Jowitt \& Germanopoulos, 1992; Toledo et al., 2008; Bøaszczyk et al., 2012; Puleo et al., 2014), otimização não linear (Bagirov et al., 2013), programação dinâmica Ulanickiet et al. (2007) e heurísticas McCormick \& Powell (2004) e Lópezlbáñez et al. (2008). Dentre os trabalhos de controle, resumimos a seguir os trabalhos que desenvolveram modelos de otimização linear para tratar o problema.

Little \& McCrodden (1989) desenvolveram um modelo de otimização linear inteira mista para um sistema de abastecimento de água na Carolina do Norte, EUA. 0 objetivo é minimizar os custos de operação do sistema, que incluem a possibilidade de utilizar geradores para evitar o uso de energia comercial no horário de pico e taxas diferenciadas de energia para operar o sistema em diversos períodos. Jowitt \& Germanopoulos (1992) desenvolveram um modelo de otimização linear para minimizar o custo de bombeamento de água em um sistema de distribuição no Reino Unido. Eles consideram a eficiência das bombas disponíveis, a estrutura da tarifa de energia elétrica, o perfil do consumidor, as restrições hidráulicas e limitações operacionais da rede. A abordagem foi aplicada e mostrou que a economia nos custos é possível. 0 método foi considerado robusto e com baixa utilização de tempo computacional, o que pode ser vantajoso na utilização em tempo real.

Bøaszczyk et al. (2012) estudaram o sistema de distribuição de água de Toronto, Canadá. 0 objetivo principal do trabalho foi o desenvolvimento de uma ferramenta capaz de gerar uma política de bombeamento para 153 bombas que atendam às necessidades quantitativas do sistema e que minimizem seus custos. Um modelo de otimização linear com uma função objetivo que expressa o custo de energia elétrica consumida nas estações de bombeamento e restrições de balanço de massa com volumes agregados dos reservatórios e reservatórios elevados foi proposto. Neste modelo, é considerado um horizonte de planejamento de 7 dias, cada dia discretizado em horas. A resolução do problema linear oferece condições de contorno para um modelo completo de otimização linear que leva em conta fenômenos hidráulicos e qualidade de água.

Puleo et al. (2014) utilizam uma abordagem baseada em programação linear (PL) para a programação de bombas, considerando um período de 24 horas, sendo as variáveis de decisão, as vazões das bombas. Durante o horizonte de planejamento, são consideradas as variações dos custos de energia elétrica. Depois da resolução do $\mathrm{PL}$, a solução é transformada em um programa discreto e verifica as combinações de bombas que satisfaçam as restrições do problema. As soluções obtidas foram comparadas com as obtidas utilizando uma abordagem da literatura e as soluções derivadas da abordagem baseada em LP são de boa qualidade.

Toledo et al. (2008) propuseram um modelo de otimização linear e um modelo linear-inteiro para o problema de planejamento com vários reservatórios, considerando a interdependência entre eles. Testes computacionais mostraram que a solução do modelo linear-inteiro por softwares comerciais é muito lenta, não tendo sido obtida a solução ótima em tempo razoável para vários exemplares testados.

Este trabalho, como os anteriores, tem como objetivo minimizar o custo da energia elétrica necessária para o funcionamento de bombas hidráulicas de sistemas de abastecimento de água. Na maioria dos sistemas de abastecimento de água, há a necessidade de utilizar estações elevatórias para recalcar água em reservatórios de distribuição e, para isso, bombas hidráulicas são utilizadas para captar água de poços (ou estações de tratamento de água) e abastecer reservatórios distribuídos pelos bairros de uma cidade, que atendem a população. Um procedimento comum observado na prática consiste em ligar as bombas hidráulicas quando o nível mínimo do reservatório é atingido e mantê-las ligadas até que o nível máximo do reservatório seja atingido. Uma vez que as tarifas de energia elétrica variam ao longo das horas do dia, este procedimento não é eficiente. Portanto, faz-se necessário um planejamento do funcionamento das bombas e, consequentemente, o controle dos níveis de estoque de água nos reservatórios, a fim de evitar o funcionamento das bombas nos horários de alto custo de energia elétrica, garantindo o atendimento da demanda.

Neste trabalho, é proposta uma heurística construtiva para o problema descrito que visa suprir duas lacunas do trabalho de Toledo et al. (2008): i) englobar vários reservatórios e suas interdependências; e ii) gerar uma solução de boa qualidade em baixo tempo 
computacional. Tais metas revelam a importância deste trabalho, o qual pode proporcionar tanto uma economia significativa aos cofres públicos, como também o melhor uso do sistema elétrico brasileiro.

A abordagem de solução proposta no presente trabalho não requer investimento em infraestrutura ou qualquer alteração na estrutura de um sistema de abastecimento existente, exige apenas mudanças nas políticas operacionais de bombeamento, as quais são de simples implantação na prática e proporcionam economias significativas nos gastos com energia elétrica.

Considerando que a demanda de água é estocástica, o planejamento deve ser refeito periodicamente, sempre que os níveis reais de água nos reservatórios divergirem dos níveis planejados. Portanto, um método de solução rápido deve ser desenvolvido, para que um planejamento (que pode se resumir em ligar/ desligar bombas) seja refeito. Segundo Cordeau et al. (2002) uma heurística deve: i) produzir soluções de qualidade; ii) ser simples e flexível. Estes são os objetivos deste artigo.

Na próxima seção, são apresentados o problema e o modelo estudados. Na Seção 3, é descrito o método de solução proposto e, na Seção 4, os experimentos computacionais realizados. Na Seção 5 , são apresentadas as conclusões e as perspectivas de trabalhos futuros.

\section{0 problema de captação e distribuição de água em redes urbanas}

\subsection{Sistemas de abastecimento de água}

Segundo Tsutiya (2006), a concepção dos sistemas de abastecimento de água é extremamente dependente do porte da cidade, da topografia, e de sua posição em relação aos mananciais. De um modo geral, os sistemas são constituídos dos seguintes elementos:

- Manancial: corpo de água superficial ou subterrâneo, do qual é retirada a água para o abastecimento populacional;

- Captação: conjunto de estruturas e dispositivos, construídos ou montados junto ao manancial, para a retirada de água destinada ao sistema de abastecimento;

- Estação Elevatória: conjunto de obras e equipamentos para recalcar a água para a unidade seguinte;

- Adutora: canalizações para conduzir água entre unidades que precedem a rede de distribuição;

- Estação de Tratamento de Água (ETA): unidade na qual a água é tratada para atender às normas e padrões de potabilidade vigentes no país;
- Reservatório: unidade do sistema na qual a água tratada é armazenada para ser distribuída aos consumidores;

- Rede de Distribuição: tubulações e acessórios para levar água potável até os consumidores.

Nas Figuras 1 e 2, são apresentadas algumas concepções de sistemas de abastecimento de água.

Basicamente, o funcionamento de um sistema de abastecimento de água consiste da captação de água de mananciais, tratamento da água em Estações de Tratamento de Água, armazenamento e distribuição ao consumidor. Há casos em que a água captada não necessita de tratamento, como podemos ver na Figura 2. Em parte do sistema, a água é captada do poço, armazenada no reservatório e distribuída para a população.

\subsection{Tarifas de energia elétrica}

No Brasil, as tarifas de energia elétrica são determinadas pela Agência Nacional de Energia Elétrica - ANEEL, que estabelece também os critérios de classificação dos consumidores e as formas de cobrança de energia elétrica. Uma unidade consumidora é classificada em função da atividade exercida e, para efeito de faturamento, os consumidores são classificados em dois grupos: Grupo A (alta tensão) e Grupo B (baixa tensão).

As empresas de saneamento básico são classificadas como consumidores do Grupo A. Os consumidores deste grupo são faturados com componentes de demanda e de consumo. A cobrança de tarifas para

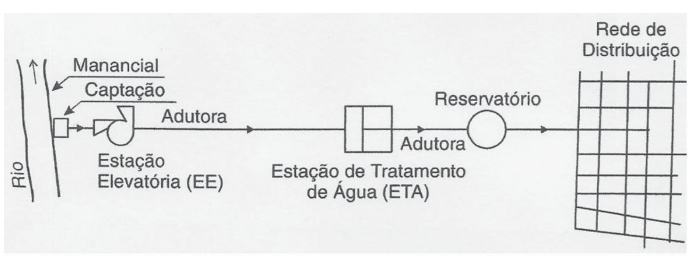

Figura 1. Sistema simples de abastecimento de água. Fonte: Tsutiya (2006).

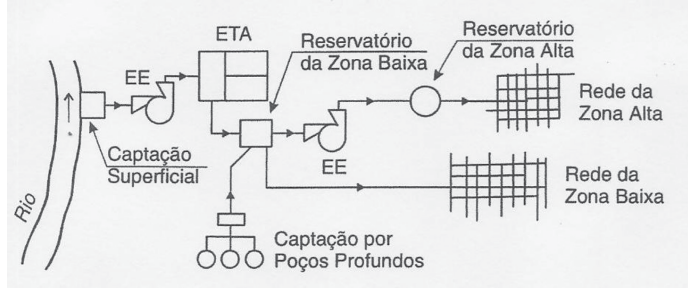

Figura 2.Sistema de abastecimento de água com captação superficial e subterrâneo. Fonte: Tsutiya (2006). 
este grupo pode ser feita segundo dois sistemas: o convencional e o horo-sazonal (azul ou verde). Estes sistemas tarifários são definidos com base na Resolução Normativa n 444/2010 da ANEEL e são brevemente descritos a seguir.

A estrutura tarifária convencional é caracterizada pela aplicação de uma tarifa para o consumo de energia elétrica $(k W h)$ e uma tarifa para a demanda de potência (kW), independentemente da hora de utilização do dia.

A estrutura tarifária azul é caracterizada pela aplicação de tarifas diferenciadas para o consumo de energia elétrica ( $k W h$ ) de acordo com a hora de utilização no dia e com os períodos do ano, bem como tarifas diferenciadas para a demanda de potência (kW) de acordo com a hora de utilização no dia. Na estrutura tarifária azul, a utilização de energia, ou seja, as tarifas da demanda de potência e de consumo de energia no horário de ponta são mais elevadas que nos demais horários. As tarifas aplicadas no período seco são ligeiramente mais elevadas que as no período úmido. 0 horário de ponta é um período de três horas contínuas a ser estabelecido pela concessionária de energia elétrica, compreendido diariamente entre $17 \mathrm{~h}$ e $22 \mathrm{~h}$, de segunda-feira à sexta-feira. No Estado de São Paulo, este intervalo é das $18 \mathrm{~h}$ às $21 \mathrm{~h}$, no horário convencional, e das $19 \mathrm{~h}$ às $22 \mathrm{~h}$, no horário de verão.

A estrutura tarifária verde é caracterizada pela aplicação de tarifas diferenciadas para o consumo de energia elétrica ( $k W h$ ) de acordo com as horas de utilização no dia e com os períodos do ano, bem como uma única tarifa para demanda de potência (kW). $\mathrm{Na}$ estrutura tarifária verde, as tarifas de consumo de energia no horário de ponta são mais elevadas do que as do horário fora de ponta.

Ainda, segundo a Resolução Normativa nº 444/2010 da ANEEL, de acordo com o valor para a demanda contratada e a tensão, os consumidores podem optar pela modalidade de cobrança de tarifas. Consumidores com demanda contratada inferior a $300 \mathrm{~kW}$ e em tensão de fornecimento inferior a $69 \mathrm{kV}$ podem escolher qualquer uma das modalidades: convencional, verde ou azul. Consumidores com demanda contratada igual ou superior a $300 \mathrm{~kW}$ e em tensão de fornecimento inferior a $69 \mathrm{kV}$ devem obrigatoriamente escolher entre as modalidades tarifárias azul ou verde. $E$ as unidades consumidoras atendidas em tensão de fornecimento igual ou superior a $69 \mathrm{kV}$ adotam obrigatoriamente a modalidade tarifária azul. A Figura 3 ilustra as modalidades tarifárias disponíveis para cada tipo de consumidor.

Como as tarifas de energia elétrica variam ao longo do dia para os consumidores que utilizam a tarifa horo-sazonal, torna-se necessário em um sistema de abastecimento de água um planejamento do horário de funcionamento das bombas hidráulicas e, consequentemente, dos níveis dos reservatórios em um horizonte de planejamento.

\subsection{O problema de planejamento de estoque de água em reservatórios}

0 problema de planejamento de estoque de água em reservatórios consiste em decidir, em cada período do horizonte de planejamento, as operações (liga/desliga) das bombas hidráulicas de captação que abastecem os reservatórios e a transferência de água entre eles, de modo que a demanda estimada de cada reservatório seja atendida em cada período e que sejam respeitados seus níveis mínimos e máximos, e o custo de energia elétrica seja mínimo. Para facilitar a operação do sistema, é considerado um custo de acionamento das bombas hidráulicas, a fim de minimizar o número de vezes que as bombas são acionadas.

A Figura 4 ilustra o problema considerando três reservatórios. Nesta figura, os arcos representam as adutoras: entre os poços/ETA e os reservatórios, entre os reservatórios, e entre os reservatórios e os centros consumidores.

A Figura 5 ilustra as relações entre os reservatórios em dois períodos consecutivos. Nesta figura, os arcos que ligam um mesmo reservatório de um período ao próximo, período $t$ ao período $t+1$, representam o estoque (reserva) de água no reservatório ao final do período

Em sistemas reais de abastecimento de água, é muito comum ocorrerem perdas de água devido aos vazamentos na rede de distribuição, as quais supomos ser proporcionais ao volume de água nos reservatórios.

Em Toledo et al. (2008), é proposto um modelo de otimização linear inteiro-misto, o qual tem como objetivo minimizar o custo da energia elétrica necessária para o funcionamento das bombas hidráulicas que

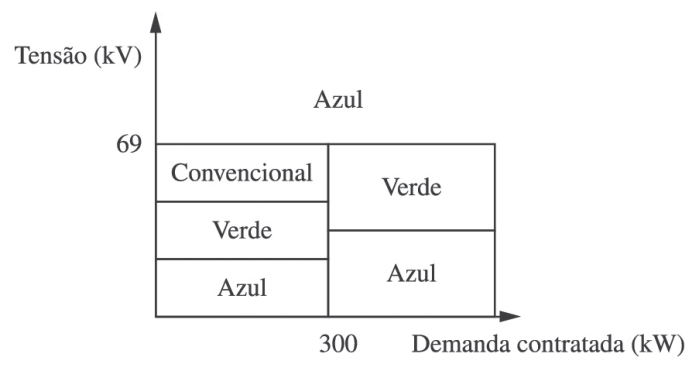

Figura 3. Modalidades tarifárias disponíveis para cada tipo de consumidor. Fonte: Os autores. 
(1)

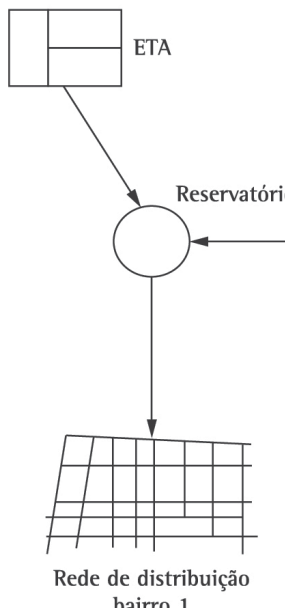

(2)

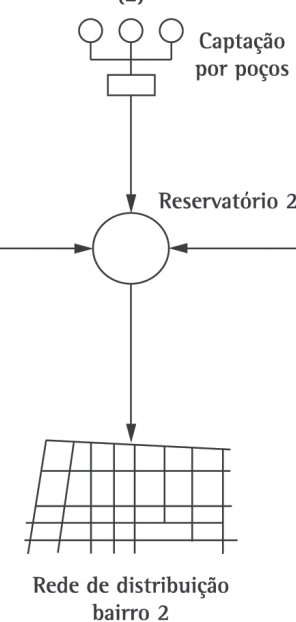

(3)

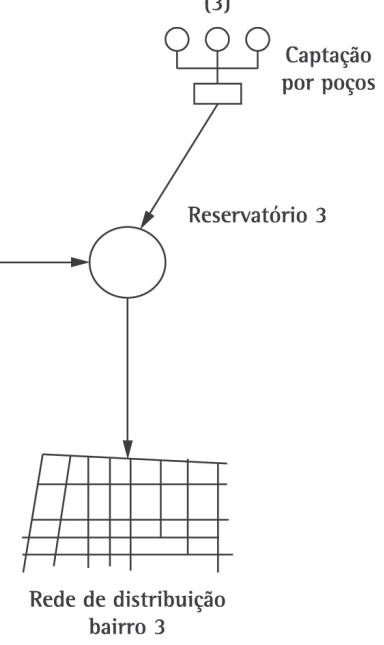

Figura 4. Esquema simplificado de uma rede de abastecimento. Fonte: Os autores.

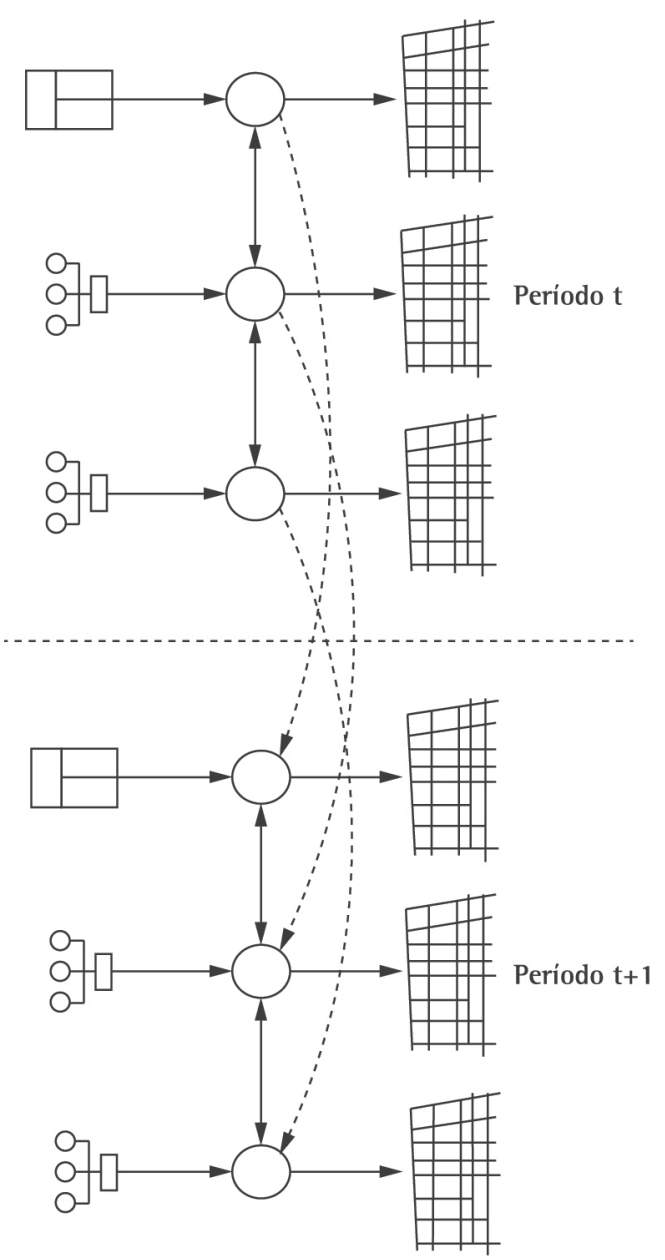

Figura 5. Balanço de água em dois períodos consecutivos. Fonte: Os autores. captam água dos poços artesianos ou de estações de tratamento de água e abastecem os reservatórios distribuídos por bairros de uma cidade. Esse modelo considera as perdas de água presentes no sistema. A seguir, é apresentado o modelo matemático de programação inteira-mista proposto em Toledo et al. (2008).

índices:

$j=1 \ldots R$; reservatórios;

$k=1 . . . B$; centros consumidores;

$t=1 \ldots T$; períodos (horizonte de planejamento).

OBS: A cada reservatório está associado um poço (ou Estação de Tratamento de Água) e uma bomba (ou conjunto de bombas). Referimo-nos ao poço $j$ ou à bomba $j$ (é considerado o conjunto de bombas associado ao reservatório como uma única bomba), sem risco de ambiguidade.

Dados:

$d_{k t}=$ previsão da demanda $\left(\mathrm{m}^{3}\right)$ do centro consumidor (bairro) $k$ durante o período $t$;

$c_{j t}=$ custo de manter ligada a bomba $j$ durante todo o período $t$;

$s c_{j t}=$ custo de acionamento da bomba $j$ no período $t$;

$v_{j t}=$ volume $\left(\mathrm{m}^{3}\right)$ de captação da bomba $j$ no período $t$ (varia de acordo com o tamanho do período);

$w_{j l t}=$ volume $\left(\mathrm{m}^{3}\right)$ de transferência da bomba que envia do reservatório $j$ para o reservatório $I$ no período $t$ (varia de acordo com o tamanho do período); 
$h_{j}^{\min }=$ volume $\left(\mathrm{m}^{3}\right)$ mínimo do reservatório $j$ (restrição de segurança);

$h_{j}^{\max }=$ volume $\left(\mathrm{m}^{3}\right)$ máximo do reservatório $j$ (restrição física);

$l_{j 0}=$ volume $\left(\mathrm{m}^{3}\right)$ do reservatório $j$ no início do horizonte de planejamento $(t=0)$;

$x_{j 0}=$ estado inicial da bomba $j\left(x_{j 0}=0\right.$ se estiver desligada ou $x_{j 0}=1$ se estiver ligada);

$S_{j}=\{k$, tal que o centro consumidor $k$ é abastecido pelo reservatório $j$ \} (tipicamente $\left|S_{j}\right|=1$ );

$R_{j}=\{l$, tal que o reservatório $l$ pode receber água do reservatório $j$;

$P_{j}=\{l$, tal que o reservatório $l$ pode enviar água para o reservatório $j\}$;

$\gamma_{j l t}=$ custo de transferir água do reservatório $j$ para o reservatório $l$ durante todo o período $t$ (pode haver elevação e uma bomba deve ser acionada, caso contrário, se por gravidade, o custo é nulo);

$\theta_{j t}=$ fração da água no reservatório $j$ perdida por vazamento durante o período $t$.

Variáveis de decisão:

$l_{j t}=$ volume de água $\left(\mathrm{m}^{3}\right)$ no reservatório $j$, estocada ao final do período $t$;

$x_{j t}=$ fração do período $t$ em que a bomba $j$ é mantida ligada;

$y_{j t}=\left\{\begin{array}{l}\left.1, \text { se } x_{j t}>0 \text { (isto é, há captação de água no período } t\right) \\ 0, \text { caso contrário; }\end{array}\right.$

$\alpha_{j t}=\left\{\begin{array}{l}1, \text { se a bomba } j \text { é acionada no período } t ; \\ 0, \text { caso contrário; }\end{array}\right.$

$Z_{j l t}=$ fração do período $t$ de água transportada do reservatório $j$ para o reservatório $l$.

0 modelo matemático:

$\operatorname{Min} \sum_{t=1}^{T} \sum_{j=1}^{R}\left(c_{j t} x_{j t}+s c_{j t} \alpha_{j t}\right)+\sum_{t=1}^{T} \sum_{j=1}^{R} \sum_{l \in R_{j}} \gamma_{j l t} z_{j l t}$

s.a $\left\{\begin{array}{lr}I_{j t}=\left(1-\theta_{j t}\right) I_{j, t-1}+v_{j t} x_{j t} & \\ \quad-\sum_{l \in R_{j}} w_{j l t} z_{j l t}+\sum_{l \in P_{j}} w_{l j t} z_{l j t}-\sum_{k \in S_{j}} d_{k t} & j=1, \ldots, \mathrm{R}, \mathrm{t}=1, \ldots, \mathrm{T} ; \\ x_{j t} \leq y_{j t} & j=1, \ldots, \mathrm{R}, \mathrm{t}=1, \ldots, \mathrm{T} ; \\ \alpha_{j t} \geq y_{j t}-x_{j, t-1} & j=1, \ldots, \mathrm{R}, \mathrm{t}=1, \ldots, \mathrm{T} ; \quad \text { (3) } \\ h_{j}{ }^{\min } \leq I_{j t} \leq h_{j}{ }^{\max } & j=1, \ldots, \mathrm{R}, \mathrm{t}=1, \ldots, \mathrm{T} ; \quad \\ 0 \leq z_{l j t} \leq 1 & l, j=1, \ldots, \mathrm{R}, \mathrm{t}=1, \ldots, \mathrm{T} ; \quad(5) \\ x_{j t} \geq 0 & j=1, \ldots, \mathrm{R}, \mathrm{t}=1, \ldots, \mathrm{T} ; \\ y_{j \mathrm{t}} \in\{0,1\}, \alpha_{j \mathrm{t}} \in\{0,1\} & j=1, \ldots, \mathrm{R}, \mathrm{t}=1, \ldots, \mathrm{T} .\end{array}\right.$

A função objetivo representa o custo total de energia elétrica necessária para o funcionamento das bombas hidráulicas de um sistema de abastecimento de água. Este custo é dado pelo custo fixo de acionar as bombas para captação mais o custo variável de mantê-las ligadas, somados aos custos de manter ligadas as bombas de transferência de água entre os reservatórios (os custos de ligar as bombas de transferência não são considerados por serem esporádicos). As Equações 1 representam o balanço de estoque de água em cada período e em cada reservatório, descontadas as perdas de água. As Restrições 2 obrigam as variáveis $y_{j t}$ a assumirem o valor 1 se $x_{j t}>0$. As Restrições 3 garantem que, se a bomba estiver ligada durante todo o período $t-1$, para utilizá-la no período $t$, não haverá custo de acionamento. As Restrições 4 garantem que os volumes de cada reservatório, em cada período, estejam entre os limites mínimo e máximo pré-estabelecidos. As Restrições 5 asseguram que as bombas para transferência de água podem permanecer desligadas durante todo o período $\left(z_{l j}=0\right)$ ou ligadas em parte do período $\left(0<Z_{l j t}<1\right)$ ou ligadas durante todo 0 período $\left(z_{l j t}=1\right)$. As Restrições 6 juntamente com as Restrições 2 asseguram que as bombas de captação podem permanecer desligadas durante todo o período $\left(x_{j t}=0\right)$ ou ligadas em parte do período $\left(0<x_{j t}<1\right)$, ou ligadas durante todo o período $\left(x_{j t}=1\right)$. Em Restrição 7 as variáveis $\alpha_{j t}$ e $y_{j t}$ são definidas como binárias.

0 modelo proposto não prevê explicitamente reações ao aumento não previsto de demanda provocado por eventos aleatórios (como calor intenso, por exemplo, ou perdas de água não previstas ocasionadas por problemas de infraestrutura no sistema). Porém, são apresentadas duas estratégias para contornar tais situações. Na primeira, o volume mínimo de água pré-estabelecido nos reservatórios deve ser capaz de atender à demanda de imediato no caso de ocorrer aumento brusco da demanda. Ou seja, o estoque mínimo de água atenua a componente estocástica da demanda que poderia causar falta de água temporária à população. Na segunda estratégia, o planejamento proposto pelo modelo pode ser aplicado sob a ótica de horizonte rolante, ou seja, resolve-se o problema considerando-se um horizonte de $T$ períodos e aplicam-se apenas as decisões dos primeiros períodos, incluem-se novos períodos no final do horizonte, atualizam-se as demandas e os níveis de água nos reservatórios e o modelo é novamente resolvido. Assim, a ocorrência de algum evento aleatório importante é atenuada pelo novo planejamento, já que os dados podem ser atualizados pelos valores corretos.

\section{Método heurístico de solução}

0 método heurístico proposto é orientado ao problema. Primeiramente, os períodos são classificados em: críticos (os pertencentes ao horário de ponta), 
pré-críticos (períodos que imediatamente antecedem o horário de ponta, nos quais é conveniente armazenar água para os períodos críticos e não críticos (demais períodos).

A heurística consiste em verificar para cada período se este é classificado como crítico, pré-crítico ou não crítico, conforme descrito na Seção 3.1, e, para cada classificação, aplicar a regra operacional de bombeamento apropriada. 0 Algoritmo 1 descreve a heurística proposta em linhas gerais.

Algoritmo 1: Heurística Construtiva

1. Classificar Períodos ( );

2. Para $t=1, \ldots, T$ faça

3. Para $j=1,, \ldots, R$ faça

4. $I_{j t}=\left(1-\theta_{j t}\right) I_{j t-1}-\sum_{k \in S_{j}} d_{k t}$;

5. Se $t \in\{$ Períodos pré-críticos\}

6. Operação Pré-Crítico $\left(l_{j t}\right)$;

7. Se $t \in\{$ Períodos não críticos\}

8. Operação Não Crítico $\left(l_{\mathrm{jt}}\right)$;

9. Se $t \in\{$ Períodos críticos $\}$

10. Operação Crítico $\left(l_{j t}\right)$;

11. Fim Para

12. Fim Para

\subsection{Classificação dos períodos}

Períodos críticos correspondem aos horários de ponta. Observa-se que, dependendo da discretização utilizada, diferentes períodos correspondem aos horários de ponta. Por exemplo, em um horizonte de planejamento de $24 \mathrm{~h}$, com períodos de $1 \mathrm{~h}$, e horário de ponta compreendido das $18 \mathrm{~h}$ às $21 \mathrm{~h}$, os períodos 19, 20 e 21 são períodos críticos.

Devido às perdas de água em um reservatório, pode ser mais barato ligar a bomba hidráulica durante um período crítico do que bombear água em um período não crítico muito anterior ao período crítico, para usá-la no período crítico. Os períodos definidos como períodos pré-críticos são aqueles que precedem imediatamente os períodos críticos, nos quais é conveniente bombear água e armazená-la para usá-la durante os períodos críticos. A definição dos períodos pré-críticos depende diretamente das perdas de água e dos preços da energia elétrica nos períodos de ponta e fora dos períodos de ponta. Para estabelecer os períodos pré-críticos, considere (por simplicidade de notação, o índice $j$ do reservatório é omitido):

$V B$ : volume bruto de água bombeada em um período não crítico;
$V L$ : volume líquido dessa água (decrescido das perdas) no início do horário crítico;

$p p$ : preço de bombear $1 \mathrm{~m}^{3}$ de água durante o horário de ponta;

$p f p$ : preço de bombear $1 \mathrm{~m}^{3}$ de água fora do horário de ponta;

$t_{p}$ : período em que inicia o horário de ponta;

Assim,

$V L=\left(1-\theta_{j t}\right)\left(1-\theta_{j, t+1}\right) \ldots\left(1-\theta_{j, t_{p}-1}\right) V B$

Se $V B . p f p<V L . p p$, então o período $t$ é classificado como pré-crítico. Substituindo-se VL na desigualdade acima, segue que um período $t$ é classificado como pré-crítico se

$$
\frac{p f p}{p p}<\left(1-\theta_{j t}\right) \cdot\left(1-\theta_{j, t+1}\right) \ldots\left(1-\theta_{j, t_{p}-1}\right)
$$

0 período pré-crítico inicial, para cada reservatório $j$, denotado pelo índice $t_{j}$ é determinado pelo algoritmo a seguir. A Figura 6 ilustra a classificação dos períodos para um reservatório $j$. 0 Algoritmo 2 classifica os períodos do horizonte de planejamento. Neste algoritmo considere:

- $t_{f p}$ : período em que se encerra o horário de ponta;

$-t_{l}, t_{2}, \ldots, t_{R}$ : são calculados pelo algoritmo e indicam o início do horário pré-crítico nos reservatórios 1 , $2, \ldots, \mathrm{R}$, respectivamente.

\section{Algoritmo 2: Classificar Períodos( )}

1. Entrada: $\mathrm{t}_{\mathrm{p}}, \mathrm{t}_{\mathrm{fp}}, \mathrm{pp}, \mathrm{pfp}, \theta_{\mathrm{jt}}$

2. Para $j=1, \ldots, R$ faça

3. $t_{j}=t_{p}-1$;

4. Enquanto $p f p / p p<\left(1-\theta_{j, t_{j}}\right) \ldots\left(1-\theta_{j, t_{p}-1}\right)$ faça

5. $t_{j}=t_{j}-1$;

6. Fim Enquanto

7. $t_{j}=t_{j}+1$;

8. Fim Para

9. Para $j=1, \ldots, R$ faça

10. Para $t=1, \ldots, T$ faça

11. Se $t<t_{j}$ ou $t>t_{f p}$ então

12. $\mathrm{t} \in\{$ Períodos não críticos\}

13. Se $t_{j} \leq t \leq t_{p}$ então

14. $\mathrm{t} \in\{$ Períodos pré-críticos $\}$

15. Se $t_{p} \leq t \leq t_{f p}$ então

16. $\mathrm{t} \in\{$ Períodos críticos\}

17. Fim Para

18. Fim Para 


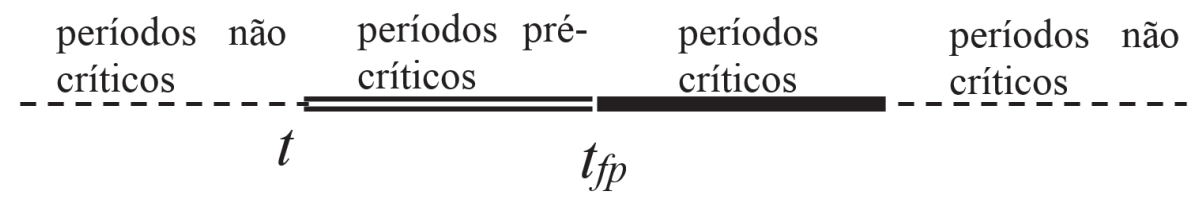

Figura 6. Períodos do reservatório $j$. Fonte: Os autores.

\subsection{Estratégia de operação bombeamento/ armazenamento para períodos não críticos}

0 planejamento, para cada reservatório, em cada período classificado como não crítico, consiste em analisar separadamente cada reservatório e manter a bomba associada a este desligada se o reservatório possuir estoque de água suficiente para satisfazer a demanda de água do período, respeitando o nível mínimo do reservatório. Se a quantidade de água armazenada não for suficiente para satisfazer a demanda do período, então deve-se escolher a operação de menor custo (não são consideradas transferências nesta operação):

Estratégia A: Acionar a bomba associada ao reservatório $j$ durante o tempo necessário para atender à demanda do período e manter o nível mínimo, isto é, $x_{j t}$ é calculado por:

$v_{j t} x_{j t}=\sum_{k \in S_{j}} d_{k t}-\left(1-\theta_{j t}\right) I_{j, t-1}+h_{j}^{\min }$

(veja Equação 1 com $l_{j t}=h_{j}^{m i n}$ ). Neste caso, o custo para satisfazer a demanda deste período é:

custo_t $t=c_{j t} x_{j t}+s c_{j t}$

Estratégia B: Reservar água dos períodos anteriores, nos quais a bomba estava ligada, para suprir a demanda do período $t$.

Seja $t_{o}$ o período precedente ao período $t$ em que houve captação de água. Como a bomba já estava ligada durante o período $t_{0}$, a capacidade de vazão da bomba pode não ser suficiente para suprir toda a demanda do período $t$. Se a demanda do período $t$, pode ser totalmente suprida durante o período $t_{0}$, $\bar{x}_{j t_{o}}$ representa a fração do período $t_{0}$ em que a bomba deve ser mantida ligada para satisfazer a demanda do período $t$, e é dada por:

$$
\bar{x}_{j t_{0}} v_{j t_{0}}=\frac{\sum_{k \in S_{j}} d_{k t}}{\left(1-\theta_{j, t_{0}+1}\right)\left(1-\theta_{j, t_{0}+2}\right) \ldots\left(1-\theta_{j t}\right)}
$$

Neste caso, o custo para satisfazer a demanda do período $t$ é:

$$
\text { custo_t } t_{0}=\bar{x}_{j t_{0}} c_{j t_{0}}
$$

Se a demanda do período $t$ não pode ser totalmente suprida durante o período $t_{0}$ (i.e., $x_{j t_{0}}+\bar{x}_{j t_{0}}>1$ ) então a bomba também deve ser mantida ligada durante o período $t_{0}+1$ e, neste caso, $\bar{x}_{j t_{0}}$ e $x_{j t_{0}+1}$ devem ser calculados, ou seja,

$\bar{x}_{j t_{0}}=1-x_{j t_{0}}$

$d a_{t_{0}}=\frac{\bar{x}_{j t_{0}} v_{j t_{0}}}{\left(1-\theta_{j, t_{0}+1}\right)\left(1-\theta_{j, t_{0}+2}\right) \ldots\left(1-\theta_{j t}\right)}$

$x_{j t_{0}+1} v_{j t_{0}+1}=\frac{\sum_{k \in S_{j}} d_{k t}-d a_{t_{0}}}{\left(1-\theta_{j, t_{0}+2}\right)\left(1-\theta_{j, t_{0}+3}\right) \ldots\left(1-\theta_{j t}\right)}$.

Neste caso, o custo para satisfazer a demanda do período $t$ é dado por:

$$
\text { custo_ } t_{0}=\bar{x}_{j t_{0}} c_{j t_{0}}+x_{j t_{0}+1} c_{j t_{0}+1} \text {. }
$$

Estes procedimentos são viáveis, pois nos sistemas de abastecimento, a capacidade de captação de água de um reservatório em cada período é maior do que a demanda desse reservatório.

A primeira estratégia tem o custo de acionar a bomba e a segunda tem o custo subjacente à perda de água. 0 Algoritmo 3 detalha como é feita a melhor escolha para o planejamento.

Algoritmo 3: Operação Não Crítico $\left(1_{\mathrm{jt}}\right)$

1. Entrada: $\mathrm{t}_{\mathrm{o}}$, custo_t, custo_t $\mathrm{t}_{0}$

2. Se custo_ $t_{0}<$ custo_t então

3. Calcular $\bar{x}_{j t_{0}}$ pela Equação 12

4. Se $\left(x_{j t_{0}}+\bar{x}_{j t_{0}}\right)>1$ então

5. $\bar{x}_{j t_{0}}=1-x_{j t_{0}}$

6. Calcular $x_{j t_{0}+1}$ pela Equação 15

7. Fim Se

8. $x_{j t_{0}}=x_{j t_{0}}+\bar{x}_{j t_{0}}$

9. $I_{j t_{0}}, I_{j t_{0}+1}, \ldots I_{j t_{-1}}$ são atualizados pela Equação 1

10. Senão

11. Calcular $x_{j t}$ pela Equação 10

12. Fim Se

13. Atualizar $l_{j t}$ pela Equação 1 


\subsection{Estratégia de operação bombeamento/ armazenamento para períodos pré-críticos}

Nestes períodos, se a capacidade do reservatório permitir manter a bomba ligada até o início do período crítico, a bomba de captação do reservatório é mantida ligada para armazenar água para os períodos críticos. As operações são apresentadas no Algoritmo 4.

Algoritmo 4: Operação Pré-Crítico $\left(l_{\mathrm{j} t}\right)$

1. Entrada: $i h p \leftarrow$ período em que se inicia o horário de ponta;

2. $I_{j, t-1}^{a u x}=I_{j, t-1}$

3. Para $l=t, t+1, \ldots, i h p-1$ faça

4. $I_{j l}^{a u x}=\left(1-\theta_{j l}\right) I_{j, l-1}+v_{j l}-\sum_{k \in S,} d_{k l}$

5. Fim Para

6. Se $I_{j t}^{a u x} \leq h_{j}^{\max }, I_{j, t+1}^{a u x} \leq h_{j}^{\max }, \ldots, I_{j, i h p-1}^{a u x} \leq h_{j}^{\max }$ então

7. Para $k=t, t+1, \ldots, i h p-1$ faça

8. $x_{j k}=1$

9. Fim Para

10. Senão

11. Operação Não Crítico $\left(l_{j l}\right)$

12. Fim Se

Neste algoritmo, a expressão da linha 4 refere-se ao volume de água no reservatório j no final do período 1 ao manter-se a bomba de captação ligada durante todo o período. Esta expressão é deduzida da Restrição 1 do modelo apresentado na Seção 2.3. No modelo temos:

$I_{j t}=\left(1-\theta_{j t}\right) I_{j, t-1}+v_{j t} x_{j t}-\sum_{m \in R_{+}} w_{j m t} z_{j m t}+\sum_{m \in P_{+}} w_{m j t} z_{m j t}-\sum_{k \in S_{S_{j}}} d_{k t}$

Tomando $t=l$, e $X_{j l}=1$ (bomba de captação ligada durante todo o periodo), $z_{j m l}=O$ (bomba de transferência de água do reservatório $j$ para o reservatório $\mathrm{m}$ desligada) e $z_{m j l}=O$ (bomba de transferência de água do reservatório $\mathrm{m}$ para o reservatório $j$ desligada) temos a expressão da linha 4 do Algoritmo 4.

$I_{j l}=\left(1-\theta_{j l}\right) I_{j, l-1}+v_{j l}-\sum_{k \in S_{j}} d_{k t}$

\subsection{Estratégia de bombeamento/ armazenamento para períodos críticos}

Para cada reservatório, é verificado se o estoque de água é suficiente para atender à demanda durante toda a faixa horária crítica. Caso não seja, tenta-se atender à demanda por transferência de água de outros reservatórios que possuam estoque de água suficiente, e em excesso, para atender a suas próprias demandas. São determinados quais reservatórios podem enviar água, direta ou indiretamente e, entre estes, é escolhido o reservatório com o menor custo de transferir água para o reservatório que não atende sua demanda no período crítico. Para isso, é utilizado o algoritmo de Floyd-Warshall, que fornece caminhos de custos mínimos entre todos os pares de nós de um grafo. Se ainda assim, a demanda do reservatório não for satisfeita, a bomba hidráulica associada a este reservatório é ligada durante o tempo necessário para atender à demanda do período crítico. Esta estratégia é detalhada no Algoritmo 5, em que $D=\left(D_{m n}\right)$ é uma matriz que representa os menores custos de transferência entre os pares de reservatórios, e é calculada utilizando o Algoritmo de Floyd-Warshall.

Algoritmo 5: Operação Crítico $\left(1_{\mathrm{jt}}\right)$

1. Se $t=t_{p}$ então

2. $D=\left(D_{m n}\right)$ - Algoritmo de Floyd-Warshall

3. Fim Se

4. Se $l_{j t}<h_{j}^{\text {min }}$ então

5. $D_{1 j}=\min \left\{D_{i j}, i=1, \ldots, R\right\}$;

6. Q_precisa $=h_{j}^{\text {min }}-l_{j t}$

7. Enquanto $Q \_$precisa $>0$ e $D_{1 j}<\infty$ faça

8. Q_transfere $=$ quantidade de água que o reservatório 1 pode transferir

9. Se Q_transfere>0 então

10. Atualizar $z_{l, i l, \mathrm{t}}, Z_{i l, i, t, i}, \ldots, Z_{i n, j, \mathrm{t}}$

11. Se Reservatório 1 envia toda água em excesso então

12. $D_{1 k}=\infty$ para $k \neq 1$;

13. Fim Se

14. Atualizar $l_{1, t}, l_{j t}$, Q_precisa

15. Fim Se

16. $D_{1 j}=\min \left\{D_{i j}, i=1, \ldots, R\right\}$

17. Fim Enquanto

18. Se Q_precisa>0 então

19. $x_{j t}=Q \_$precisal $v_{j t}$

20. Fim Se

21. Fim Se

\section{Experimentos computacionais}

\subsection{Gerador de exemplares}

Para validar a heurística proposta e avaliar sua eficiência, foi implementado em linguagem $C$ um gerador de exemplares. 0 programa gera exemplares para um horizonte de planejamento de 2 dias, divididos em períodos de uma hora, de modo que o horizonte de planejamento possui 48 períodos. Foi escolhido 
este horizonte de planejamento a fim de englobar dois horários de ponta, horários $18 \mathrm{~h}-21 \mathrm{~h}$, isto é, períodos 19-21 e 43-45, para avaliar o comportamento das soluções nestes horários. 0 sistema de abastecimento é fixado conforme as Figuras 7-10. As capacidades dos reservatórios e taxas de captação das bombas são especificadas para cada classe de exemplar, enquanto as demandas foram geradas aleatoriamente, uniformemente distribuídas.

\subsection{Classe de exemplares}

\subsection{1. $1^{\text {a }}$ Classe de exemplares}

Estes exemplares foram apresentados em Toledo et al. (2008). Nestes exemplares, são considerados 3 reservatórios e 3 poços, cada poço associado a um reservatório e a uma bomba de captação. Os volumes mínimos e máximos dos reservatórios, assim como os volumes no início do horizonte de planejamento e a vazão das bombas de captação associadas aos reservatórios são apresentados na Tabela 1.

0 custo de manter ligada cada bomba durante cada um dos períodos é igual a 30 unidades monetárias, exceto às $18 \mathrm{~h}, 19 \mathrm{~h}$ e $20 \mathrm{~h}$, quando o custo é de 60 unidades monetárias (estes valores foram tomados

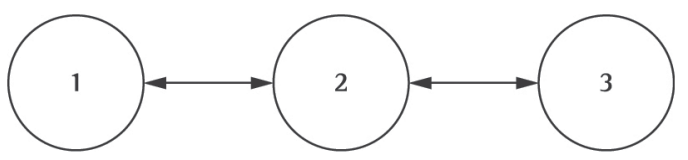

Figura 7. Sistema de abastecimento constituído por 3 reservatórios $-1^{\text {a }}$ e $2^{\text {a }}$ classes de exemplares. Fonte: Os autores. com base na tarifa horo-sazonal azul). 0 custo de acionar cada bomba foi arbitrado igual a 1 unidade monetária, em todos os períodos, o que é suficiente para evitar uma solução excessivamente intermitente. As demandas variam entre $5 \mathrm{~m}^{3}$ e $270 \mathrm{~m}^{3}$ por hora e foram geradas uniformemente distribuídas em intervalos que representam as estimativas máximas e mínimas em cada faixa horária, o que se aproxima do comportamento real do consumo em uma cidade típica de porte médio, de acordo com os dados apresentados em Toledo et al. (2008).

Pode haver transferência de água entre os reservatórios: de 1 para 2, 2 para 1, 2 para 3 e 3 para 2 com custo de 3 unidades monetárias por período (isto é, $w_{12 t}=w_{21 t}=w_{23 t}=w_{32 t}=3$ ). Este valor foi definido considerando haver um pequeno desnivel entre esses reservatórios de forma que a energia gasta pela bomba se destina a vencer majoritariamente a perda de carga. A vazão de transferência é de $60 \mathrm{~m}^{3}$ por hora. Não é permitida a transferência direta entre os reservatórios 1 e 3. Os nós do grafo na Figura 7 representam estes três reservatórios, as arestas orientadas indicam as possiveis transferências entre os reservatórios.

\subsection{2. $2^{\text {a }}$ Classe de exemplares}

Tabela 1. Capacidades dos reservatórios e vazão das bombas de captação $-1^{\text {a }}$ classe de exemplares.

\begin{tabular}{ccccc}
\hline \multirow{2}{*}{ Reservatórios } & \multicolumn{3}{c}{ Volume $\left(\mathrm{m}^{3}\right)$} & \multirow{2}{*}{$\begin{array}{c}\text { Vazão } \\
\mathrm{m}^{3} / \mathrm{h}\end{array}$} \\
\cline { 2 - 4 } & Mínimo & Máximo & Inicial & \\
\hline 1 & 270 & 2000 & 500 & 300 \\
2 & 270 & 1000 & 500 & 300 \\
3 & 270 & 1000 & 500 & 300 \\
\hline
\end{tabular}

Fonte: Os autores.

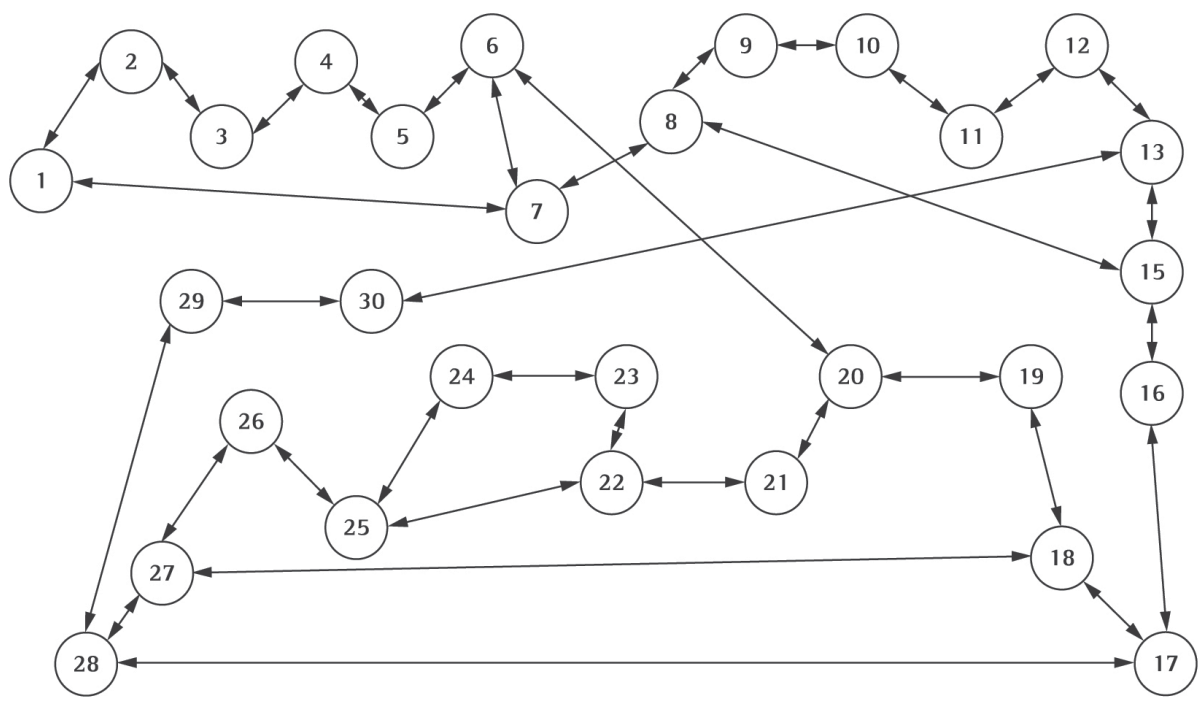

Figura 8. Sistema de abastecimento constituído por 30 reservatórios - 3a classe de exemplares. Fonte: Os autores. 
As características dos dados são as mesmas descritas para a $1^{\text {a }}$ classe de exemplares, exceto o custo de manter ligada cada bomba às $18 \mathrm{~h}, 19 \mathrm{~h}$ e $20 \mathrm{~h}$, que foi tomado como sendo de 120 unidades monetárias, valor este tomado com base na tarifa horo-sazonal verde.

\subsection{3. $3^{a}$ Classe de exemplares}

Estes exemplares englobam 30 reservatórios, com volumes mínimos de $270 \mathrm{~m}^{3}$ para todos os reservatórios e volumes máximos de $2000 \mathrm{~m}^{3}$ para os reservatórios $6,15,22$ e 28 , e de $1000 \mathrm{~m}^{3}$ para os demais reservatórios. Os volumes iniciais dos reservatórios foram tomados como sendo de $500 \mathrm{~m}^{3}$.

A cada reservatório estão associados um poço e uma bomba de captação. A vazão das bombas é de $300 \mathrm{~m}^{3}$ por hora. Os custos de manter ligada cada bomba e os custos de acionamento das bombas estão

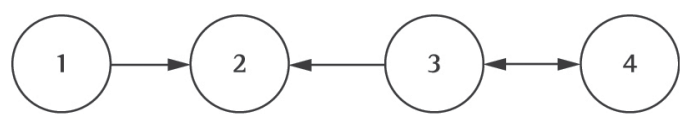

Figura 9. Sistema de abastecimento constituído por 4 reservatórios - 4a classe de exemplares. Fonte: Os autores.

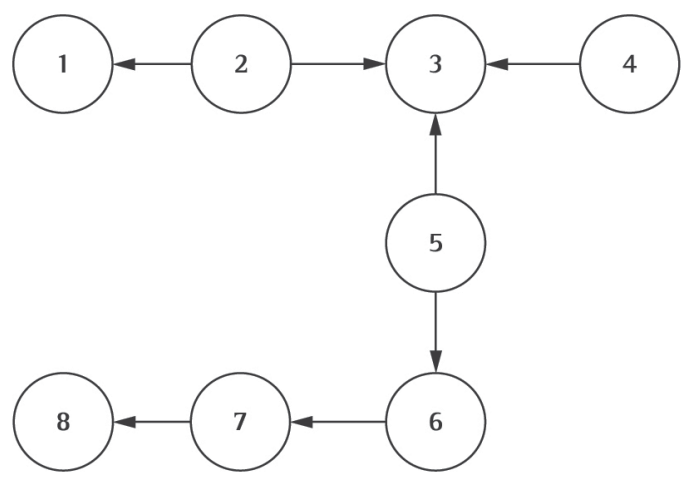

Figura 10. Sistema de abastecimento constituído por 8 reservatórios - $5^{\text {a }}$ classe de exemplares. Fonte: Os autores. de acordo com a $1^{\text {a }}$ classe de exemplares (i.e., baseados na tarifa horo-sazonal azul). As demandas também foram geradas do mesmo modo que na $1^{\text {a }}$ classe de exemplares.

0 grafo apresentado na Figura 8 representa este sistema de abastecimento. Para todas as possíveis transferências foi considerado um custo de 3 unidades monetárias por período e vazão de $60 \mathrm{~m}^{3}$ por hora.

Os testes com esta classe de exemplares permitiram avaliar a eficiência da heurística para sistemas com um número grande de reservatórios.

As próximas classes de exemplares são baseadas em informações sobre o sistema de abastecimento da cidade de São Carlos, fornecidas por funcionários do SAAE - São Carlos (Serviço Autônomo de Água e Esgoto de São Carlos) e as demandas foram geradas uniformemente distribuídas em intervalos que representam as estimativas máximas e mínimas (para cada reservatório) em cada faixa horária; estas estimativas foram determinadas com base em Toledo et al. (2008). Nesse sistema de abastecimento, há vários reservatórios e conjuntos de reservatórios e não há interligação com os demais reservatórios do sistema, portanto, podem ser analisados independentemente dos demais reservatórios. As próximas três classes de exemplares juntas representam quase todo o sistema de abastecimento de São Carlos, totalizando 21 reservatórios.

\subsection{4. $4^{a}$ Classe de exemplares}

Os dados foram baseados em 4 reservatórios da cidade de São Carlos. Os reservatórios 1, 2 e 3 estão associados a três poços distintos e o reservatório 4 à Estação de Tratamento de Água, e cada um destes reservatórios está associado a uma bomba de captação. Os volumes mínimos, máximos e iniciais de cada reservatório, as vazões das bombas de captação e o custo para mantê-las ligadas em cada período são apresentados na Tabela 2.

Os custos de manter ligada cada bomba desta classe de exemplares, bem como, para a $5^{\mathrm{a}}$ e $6^{\mathrm{a}}$ classes, são
Nivel do Reservatório 1 - Cplex

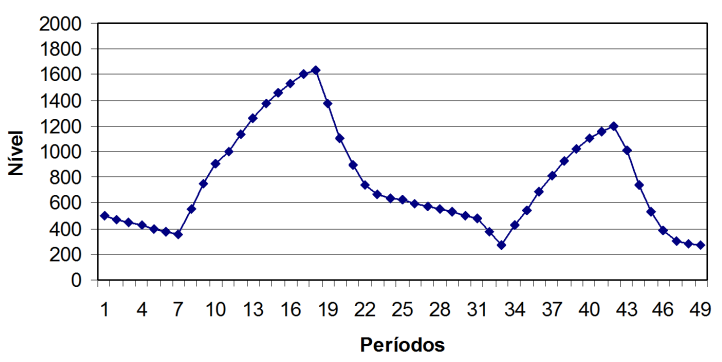

Nivel do Reservatório 1 - Heurística

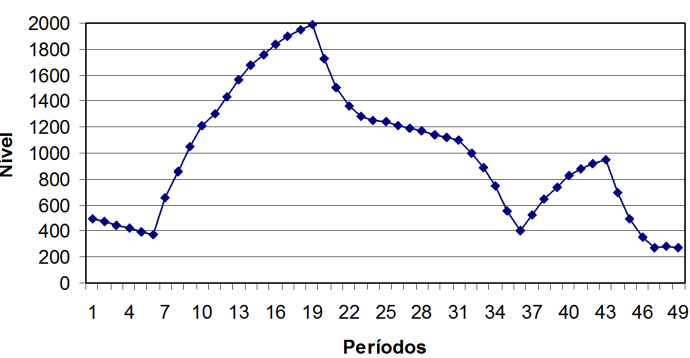

Figura 11. Nível do Reservatório 1 - Experimento 1. Fonte: Os autores. 
Tabela 2. Capacidades dos reservatórios, vazão e custos das bombas de captação - 4a classe de exemplares.

\begin{tabular}{|c|c|c|c|c|c|c|}
\hline \multirow{3}{*}{ Reservatório } & \multicolumn{3}{|c|}{ Volume $\left(\mathrm{m}^{3}\right)$} & \multicolumn{3}{|c|}{ Bomba } \\
\hline & \multirow{2}{*}{ Mínimo } & \multirow{2}{*}{ Máximo } & \multirow{2}{*}{ Inicial } & \multirow{2}{*}{ Vazão $\left(m^{3} / h\right)$} & \multicolumn{2}{|c|}{ Custo por período } \\
\hline & & & & & Fora Ponta & Ponta \\
\hline 1 & 60 & 200 & 100 & 70 & 100 & 200 \\
\hline 2 & 225 & 750 & 375 & 120 & 100 & 200 \\
\hline 3 & 32 & 106 & 53 & 107 & 130 & 260 \\
\hline 4 & 780 & 2600 & 1300 & 750 & 800 & 1600 \\
\hline
\end{tabular}

Fonte: Os autores.

Tabela 3. Vazão e custo das bombas de transferência - 4ª classe de exemplares.

\begin{tabular}{ccc}
\hline Bomba & Vazão $\left(\mathrm{m}^{3} / \mathrm{h}\right)$ & Custo por período \\
\hline $1 \rightarrow 2$ & 70 & 3 \\
$3 \rightarrow 2$ & 40 & 15 \\
$3 \rightarrow 4$ & 80 & 3 \\
$4 \rightarrow 3$ & 80 & 30 \\
\hline
\end{tabular}

Fonte: 0s autores.

diferenciados, pois o consumo de energia destas não é igual e são gerados adotando a tarifa horo-sazonal azul. 0 custo de acionar cada bomba de captação foi arbitrado igual a 1 unidade monetária.

A Figura 9 representa este sistema de abastecimento. As vazões das bombas de transferência e o custo para mantê-las ligadas em cada período são apresentados na Tabela 3. A transferência do reservatório 1 para o reservatório 2 ocorre por gravidade e, por isso, o custo é baixo, o mesmo ocorre do reservatório 3 para o reservatório 4 .

\subsection{5. $5^{a}$ Classe de exemplares}

Os dados foram baseados em 8 reservatórios da cidade de São Carlos. Os reservatórios 5 e 7 estão associados à ETA, e os demais reservatórios a poços distintos. Os volumes mínimos, máximos e iniciais de cada reservatório, as vazões das bombas de captação e o custo de manter estas ligadas em cada período são apresentados na Tabela 4 . 0 custo de acionar cada bomba de captação foi arbitrado igual a 1 unidade monetária.

A Figura 10 representa este sistema de abastecimento. As vazões das bombas de transferência e o custo de manter estas ligadas em cada período são apresentados na Tabela 5. As transferências do reservatório 2 para o reservatório 1 , do reservatório 4 para o 3 , do reservatório 6 para o 7 , e do reservatório 7 para 8 ocorrem por gravidade.

\subsection{6. $6^{a}$ Classe de exemplares}

Os dados foram baseados em 9 reservatórios da cidade de São Carlos. 0 reservatório 3 está associado à ETA e os demais reservatórios a poços distintos. Os volumes mínimos, máximos e iniciais de cada reservatório, as vazões das bombas de captação e 0 custo de manter estas ligadas em cada período são apresentados na Tabela 6 . 0 custo de acionar cada bomba de captação foi arbitrado igual a 1 unidade monetária.

A única possível transferência é do reservatório 1 para o reservatório 2 e ocorre por gravidade, com custo de 3 unidades monetárias por período e vazão de $100 \mathrm{~m}^{3} / \mathrm{h}$.

\subsection{Solução CPLEX $\times$ solução heurística}

Para analisar a eficiência da heurística proposta foi utilizado o pacote CPLEX como referência, isto é, as soluções obtidas pela heurística foram comparadas com as soluções obtidas pelo CPLEX. Em todos os testes, a execução do CPLEX 12 com sua configuração padrão foi limitada em 600 segundos, enquanto que a heurística sempre apresenta a solução em fração de segundos. Todos os testes foram realizados em um computador com Processador Intel ${ }^{\otimes}$ Core $^{\mathrm{TM}}$ i3 CPU M $380 @ 2.53 \mathrm{GHz}$ e memória RAM de 4,00 GB.

Em cada experimento, são comparados os gaps médios obtidos pelo pacote CPLEX e pela heurística (cada sistema de abastecimento é definido pela rede adutora entre reservatórios, cujas capacidades são fixadas, bem como as vazões das bombas de captação, e um conjunto de 5 exemplares é gerado por se escolher as demandas aleatoriamente). 0 gap médio é dado pela média aritmética dos gaps. 0 gap de cada experimento é calculado por:

gap $=\frac{f^{\text {meth }}-f^{L}}{f^{L}} \times 100$,

em que meth = CPLEX ou meth = HEURISTICA, sendo $f^{\text {meth }}$ o valor da função objetivo avaliada na solução obtida pelo método (CPLEX ou HEURÍSTICA) e $f^{L}$ é o valor ótimo da função objetivo da relaxação linear do problema, um limitante inferior.

A Tabela 7 apresenta a média dos gaps obtidos pelo CPLEX e pela heurística nos experimentos 1 a 10 . Os experimentos 1 a 6 verificaram a eficiência da heurística proposta para diferentes quantidades de perdas de água, tanto em sistemas de abastecimento que adotam tarifa horo-sazonal azul como em sistemas 
Tabela 4. Capacidades dos reservatórios, vazão e custos das bombas de captação - 5 a classe de exemplares.

\begin{tabular}{|c|c|c|c|c|c|c|}
\hline \multirow{3}{*}{ Reservatório } & \multicolumn{3}{|c|}{ Volume $\left(\mathrm{m}^{3}\right)$} & \multicolumn{3}{|c|}{ Bomba } \\
\hline & \multirow{2}{*}{ Mínimo } & \multirow{2}{*}{ Máximo } & \multirow{2}{*}{ Inicial } & \multirow{2}{*}{ Vazão $\left(\mathrm{m}^{3} / \mathrm{h}\right)$} & \multicolumn{2}{|c|}{ Custo por período } \\
\hline & & & & & Fora Ponta & Ponta \\
\hline 1 & 645 & 2150 & 1075 & 215 & 235 & 470 \\
\hline 2 & 660 & 2200 & 1100 & 298 & 350 & 700 \\
\hline 3 & 750 & 2500 & 1250 & 282 & 350 & 700 \\
\hline 4 & 60 & 200 & 100 & 90 & 120 & 240 \\
\hline 5 & 1140 & 3800 & 1900 & 750 & 800 & 1600 \\
\hline 6 & 660 & 2200 & 1100 & 86 & 130 & 260 \\
\hline 7 & 1500 & 5000 & 2500 & 300 & 250 & 500 \\
\hline 8 & 270 & 900 & 450 & 122 & 160 & 320 \\
\hline
\end{tabular}

Fonte: Os autores.

Tabela 5. Vazão e custo das bombas de transferência - $5^{\text {a }}$ classe de exemplares.

\begin{tabular}{ccc}
\hline Bomba & Vazão $\left(\mathrm{m}^{3} / \mathrm{h}\right)$ & Custo por periodo \\
\hline $2 \rightarrow 1$ & 80 & 3 \\
$2 \rightarrow 3$ & 250 & 40 \\
$4 \rightarrow 3$ & 50 & 3 \\
$5 \rightarrow 3$ & 650 & 120 \\
$5 \rightarrow 6$ & 450 & 75 \\
$6 \rightarrow 7$ & 50 & 3 \\
$7 \rightarrow 8$ & 70 & 3 \\
\hline
\end{tabular}

Fonte: Os autores.

de abastecimento que adotam a tarifa horo-sazonal verde. 0 experimento 7 verificou a eficiência da heurística em resolver exemplares com grande número de reservatórios interligados. Os experimentos 8, 9 e 10 foram realizados com a finalidade de avaliar a eficiência da heurística em resolver exemplares que representam sistemas reais de abastecimento de água.

A seguir são descritos os experimentos realizados.

\subsection{Análise dos experimentos}

\subsubsection{Experimento 1}

Os dados foram gerados conforme descrito na $1{ }^{\text {a }}$ classe, supondo não haver perdas de água para cada reservatório $\left(\theta_{j t}=0\right.$ para $j=1,2,3$ e $\left.t=1,2,3, \ldots, 48\right)$ e 5 exemplares foram gerados pela escolha aleatória da demanda.

Tanto as soluções obtidas pelo CPLEX 12 quanto as soluções obtidas pela heurística seguem uma mesma política de armazenamento de água: no início do horário de ponta os reservatórios estão no seu nível máximo ou com estoque de água o suficiente para atender à demanda durante o horário de ponta. Além disso, em ambas as soluções, na maioria das vezes em que a bomba é acionada, esta é mantida ligada até que o nível máximo do reservatório seja atingido. Como ilustração deste comportamento, são apresentados na Figura 11 os gráficos que representam o nível do reservatório 1 para um dos exemplares testados. A Figura 11a apresenta a solução obtida pelo CPLEX e a Figura $11 \mathrm{~b}$ a solução obtida pela heurística.

Nos exemplares testados, tanto as soluções obtidas pelo CPLEX quanto as soluções obtidas pela heurística são de boa qualidade. A desvantagem do pacote CPLEX é o tempo de execução que é muito grande quando comparado com a heurística. Esta desvantagem foi observada em todos os testes. Deve-se ter em mente a natureza estocástica da demanda e, portanto, a solução apresentada está idealizada e deve ser redefinida periodicamente, quando os níveis reais dos reservatórios diferirem dos níveis programados baseados nas previsões das demandas $d_{k p}$ e por isso é necessário que a busca por uma solução ótima exija pouco tempo.

\subsubsection{Experimento 2}

Os dados foram gerados conforme descrito na $1^{\text {a }}$ classe de exemplares, para perdas de água da ordem de 10\% para cada reservatório. Foram testados 5 exemplares.

Tanto nas soluções obtidas pelo CPLEX 12 quanto nas soluções obtidas pela heurística, no início do horário de ponta os reservatórios apresentam estoque de água, mas não estão no seu nível máximo. lsto ocorre pois, devido às perdas de água, nem sempre é conveniente armazenar água. Nas soluções obtidas pelo CPLEX, os reservatórios armazenam água em alguns períodos fora do horário de ponta e, nestes horários, os níveis dos reservatórios se mantêm próximos do nível mínimo. Nas soluções obtidas pela heurística, nos horários fora de ponta, os reservatórios se mantêm com seus níveis mínimos. A Figura 12 ilustra o nível do reservatório 1 para um dos exemplos testados. A Figura 12a apresenta a solução obtida pelo CPLEX e a Figura 12b, a solução obtida pela heurística. 
Tabela 6. Capacidades dos reservatórios, vazão e custos das bombas de captação - $6^{\text {a }}$ classe de exemplares.

\begin{tabular}{|c|c|c|c|c|c|c|}
\hline \multirow{3}{*}{ Reservatório } & \multicolumn{3}{|c|}{ Volume $\left(\mathrm{m}^{3}\right)$} & \multicolumn{3}{|c|}{ Bomba } \\
\hline & \multirow{2}{*}{ Mínimo } & \multirow{2}{*}{ Máximo } & \multirow{2}{*}{ Inicial } & \multirow{2}{*}{ Vazão $\left(\mathrm{m}^{3} / \mathrm{h}\right)$} & \multicolumn{2}{|c|}{ Custo por período } \\
\hline & & & & & Fora Ponta & Ponta \\
\hline 1 & 60 & 200 & 100 & 100 & 110 & 220 \\
\hline 2 & 60 & 200 & 100 & 22 & 30 & 60 \\
\hline 3 & 120 & 400 & 200 & 30 & 40 & 80 \\
\hline 4 & 30 & 100 & 50 & 48 & 70 & 140 \\
\hline 5 & 300 & 1000 & 500 & 100 & 130 & 260 \\
\hline 6 & 30 & 100 & 50 & 83 & 140 & 280 \\
\hline 7 & 150 & 500 & 250 & 88 & 120 & 240 \\
\hline 8 & 9 & 30 & 15 & 35 & 50 & 100 \\
\hline 9 & 74 & 2480 & 1240 & 328 & 328 & 656 \\
\hline
\end{tabular}

Fonte: Os autores.

Tabela 7. Gap médio.

\begin{tabular}{ccccc}
\hline Experimento & Classe & Perda & Gap CPLEX & Gap Heuristica \\
\hline 1 & $1^{\text {a }}$ & $0 \%$ & $0,30 \%$ & $0,66 \%$ \\
2 & $1^{\text {a }}$ & $10 \%$ & $0,82 \%$ & $1,1 \%$ \\
3 & $1^{\text {a }}$ & $20 \%$ & $0,74 \%$ & $0,49 \%$ \\
4 & $2^{\text {a }}$ & $0 \%$ & $0,24 \%$ & $0,73 \%$ \\
5 & $2^{\text {a }}$ & $10 \%$ & $0,02 \%$ & $0,24 \%$ \\
6 & $2^{\text {a }}$ & $20 \%$ & $0,14 \%$ & $2,65 \%$ \\
7 & $3^{\text {a }}$ & $10 \%$ & $2,62 \%$ & $2,05 \%$ \\
8 & $4^{\text {a }}$ & $10 \%$ & $0,73 \%$ & $3,27 \%$ \\
9 & $5^{\text {a }}$ & $10 \%$ & $1,22 \%$ & $1,94 \%$ \\
\hline
\end{tabular}

Fonte: Os autores.

Nível do Reservatório 1 - Cplex

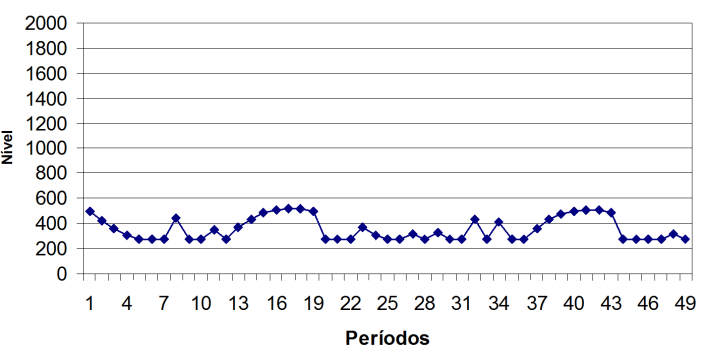

(a)

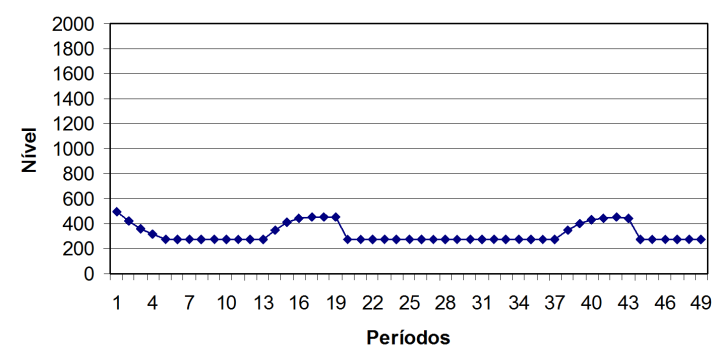

Figura 12. Nível do Reservatório 1 - Experimento 2. Fonte: Os autores.

Novamente, nos exemplares testados, tanto as soluções obtidas pelo CPLEX quanto as soluções obtidas pela heurística são de boa qualidade.

\subsubsection{Experimento 3}

Os dados foram gerados conforme descrito na $1^{\text {a }}$ classe de exemplares, para perdas de água da ordem de 20\% para cada reservatório. Foram testados 5 exemplares.

Tanto as soluções obtidas pelo CPLEX 12 quanto as soluções obtidas pela heurística, no início do horário de ponta, os reservatórios apresentam estoque de água muito pequeno. Isto ocorre pois, devido à grande quantidade de perdas de água, o custo subjacente à perda de água é muito maior do que o custo de manter a bomba de captação ligada durante o horário de ponta. Nos períodos pertencentes aos horários fora de ponta, os níveis dos reservatórios se mantêm próximos do nível mínimo. A Figura 13 ilustra o nível do reservatório 1 para um dos exemplos testados. A Figura 13a apresenta a solução obtida pelo CPLEX e a Figura 13b, a solução obtida pela heurística. 
Nivel do Reservatório 1 - Cplex

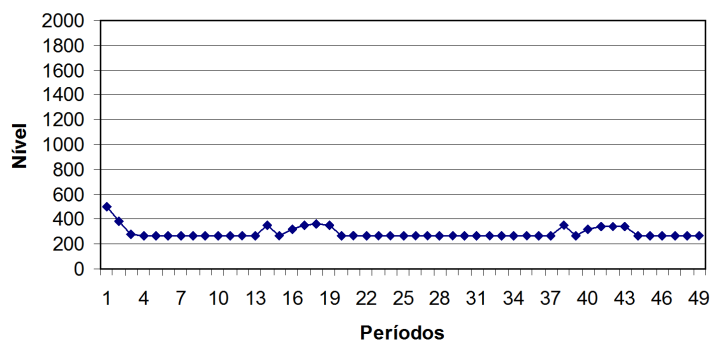

Nivel do Reservatório 1 - Heurística

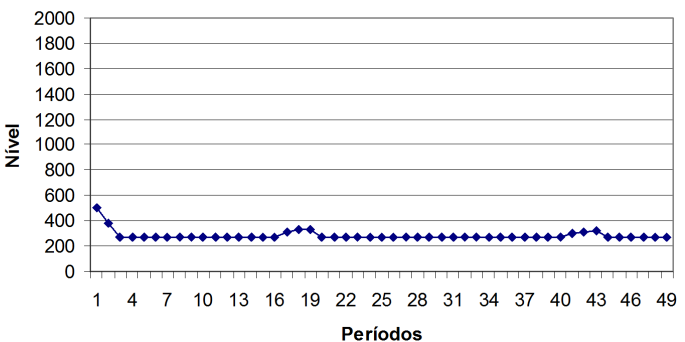

Figura 13. Nível do Reservatório 1 - Experimento 3. Fonte: Os autores.

\subsubsection{Experimentos 4 a 10}

Para cada experimento, foram testados 5 exemplares.

Os dados dos experimentos 4, 5 e 6 foram gerados conforme descrito na $2^{\text {a }}$ classe de exemplares, supondo não haver perdas de água para cada reservatório, perdas de $10 \%$ e perdas de $20 \%$, respectivamente. Estes experimentos diferenciam dos experimentos 1,2 e 3 apenas pelo sistema tarifário adotado. Os comportamentos das soluções obtidas pelo CPLEX e pela heurística foram semelhantes às soluções obtidas nos experimentos 1 , 2 e 3 , porém, nos experimentos 4 , 5 e 6 , no início do horário de ponta, os reservatórios apresentam mais estoque de água, pois foi adotada a tarifa horo-sazonal verde, cujo custo no horário de ponta é mais elevado do que na tarifa horo-sazonal azul, adotada nos experimentos 1, 2 e 3 .

Os dados dos experimentos 7 foram gerados conforme descrito na $3^{\text {a }}$ classe de exemplares, para perdas de água de 10\% do volume do reservatório por período. Novamente, tanto na solução obtida pelo CPLEX, quanto na solução obtida pela heurística, observou-se que os reservatórios apresentam estoque de água no início do horário de ponta. Ambas as soluções são de boa qualidade.

Os dados dos experimentos 8, 9 e 10 foram gerados conforme descrito na $4^{a}$, $5^{a}$ e $6^{a}$ classes, respectivamente, para perdas de água da ordem de 10\% para cada reservatório (dados do sistema de abastecimento da cidade de São Carlos). Tanto nas soluções obtidas pelo CPLEX 12 quanto nas soluções obtidas pela heurística, no início do horário de ponta, os reservatórios armazenam água abaixo do nível máximo. Observa-se na Tabela 7 que, para estes exemplares, embora a solução heurística seja de boa qualidade, as soluções obtidas pelo CPLEX são consideravelmente melhores, a heurística não explora variações nos custos operacionais das bombas, característica presente nestes exemplares. Devido a estas variações nos custos operacionais das bombas, nas soluções obtidas pelo CPLEX, há transferência de água entre os reservatórios mesmo nos períodos fora de horário de ponta e a heurística não considera esta possibilidade.

\subsection{Análise da redução dos custos com energia elétrica ao adotar a heurística proposta}

Para avaliar o impacto na redução dos custos com energia elétrica ao adotar-se a estratégia proposta para programação da captação, do armazenamento e da distribuição de água, foram realizadas simulações que objetivam reproduzir o procedimento normalmente adotado na prática para a operação das bombas hidráulicas nos sistemas de abastecimento.

0 procedimento adotado na prática consiste em ligar a bomba de captação associada ao reservatório quando o nível mínimo deste é atingido e mantê-la ligada até que o nível máximo seja atingido. No início do horário de ponta, caso a bomba esteja ligada, esta é então desligada e é mantida assim até que o nível mínimo do reservatório seja alcançado, o que pode ocorrer ainda na faixa horária correspondente ao horário de ponta. As bombas para transferência de água entre os reservatórios somente são acionadas se a demanda do reservatório no período não puder ser atendida mantendo a sua bomba de captação ligada, ou se o reservatório não possuir bomba de captação.

Foram realizados testes numéricos a fim de comparar os custos com energia elétrica ao adotar-se o procedimento usual, com os custos com energia elétrica ao adotar-se a estratégia proposta neste trabalho. Os testes foram realizados com exemplares cujos dados foram baseados no sistema de abastecimento da cidade de São Carlos ( $4^{\mathrm{a}}, 5^{\mathrm{a}}$ e $6^{\mathrm{a}}$ classe de exemplares). Escolheu-se um exemplar de cada uma destas classes para resolver pelo método usual e pela heurística proposta neste trabalho. Os custos com energia elétrica obtidos em cada um dos casos são apresentados na Tabela 8.

Nota-se pela Tabela 8 que houve uma redução considerável nos custos com energia elétrica ao adotar-se a heurística proposta neste trabalho. Embora 
Tabela 8. Custo com energia elétrica: método usual x heurística.

\begin{tabular}{cccc}
\hline \multirow{2}{*}{ Exemplar } & \multicolumn{2}{c}{$\begin{array}{c}\text { Custo com Energia Elétrica } \\
\text { (Unidades Monetárias) }\end{array}$} & \multirow{2}{*}{ Redução (\%) } \\
\cline { 2 - 3 } & Método Usual & Heurística & \\
\hline $4^{\text {a } \text { Classe }}$ & 37996,53 & 30759,85 & 19,05 \\
$5^{\text {a } \text { Classe }}$ & 101605,25 & 78444,33 & 22,80 \\
$6^{\text {a }}$ Classe & 40383,62 & 31737,39 & 21,41 \\
\hline
\end{tabular}

Fonte: Os autores.

o método adotado na prática objetive desligar as bombas no início do horário de ponta, como não há planejamento nem sempre os reservatórios possuem estoque de água suficiente para atender à demanda de todo o período de ponta e, portanto, as bombas precisam ser acionadas.

\section{Conclusões e perspectivas}

A heurística proposta mostrou-se capaz de produzir soluções de boa qualidade em frações de segundo, o que viabiliza seu uso prático, pois, devido à urgência de atender a demandas imprecisas, faz-se necessário a reotimização do problema com os níveis iniciais dos reservatórios atualizados periodicamente.

Nota-se que, embora a solução heurística seja de boa qualidade, as soluções obtidas pelo CPLEX são melhores, pois a heurística não explora variações nos custos operacionais das bombas. Porém, o pacote CPLEX utiliza um alto tempo computacional. Como um trabalho futuro, a heurística deve ser adaptada para considerar variações dos custos operacionais em diferentes bombas.

Um outro uso do modelo, além da operação do sistema, é o projeto de expansões. Por exemplo, pode-se avaliar o impacto nos custos de energia elétrica pelo aumento da capacidade de alguns reservatórios, ou construção de novas ligações entre reservatórios, bem como ampliações das ligações existentes. Pode-se também avaliar em quanto tempo o investimento em bombas hidráulicas mais eficientes é pago pelos ganhos dos custos operacionais.

\section{Referências}

Bagirov, A. M., Barton, A. F., Mala-Jetmarova, H., Al Nuaimat, A., Ahmed, S. T., Sultanova, N., \& Yearwood, J. (2013). An algorithm for minimization of pumping costs in water distribution systems using a novel approach to pump scheduling. Mathematical and Computer Modelling, 57(3-4), 873-886. http://dx.doi.org/10.1016/j.mcm.2012.09.015.
Bøaszczyk, J., Karbowski, A., Krawczyk, K., Malinowski, K., \& Allidina, A. (2012). Optimal pump scheduling for large scale water transmission system by linear programming. Journal of Telecommunications and Information Technology, 3, 91-96.

Cordeau, J.-F., Gendreau, M., Laporte, G., Potvin, J.-Y., \& Semet, F. (2002). A guide to vehicle routing heuristics. The Journal of the Operational Research Society, 53(5), 512-522. http://dx.doi.org/10.1057/palgrave.jors.2601319.

Instituto Brasileiro de Geografia e Estatística. (2011). Atlas de Saneamento. Recuperado em 18 de Abril de 2013, de http://www.ibge.gov.br/home/estatistica/populacao/ atlas_saneamento/default_zip.shtm.

Jowitt, P. W., \& Germanopoulos, G. (1992). Optimal pump scheduling in water-supply networks. Journal of water Resources Planning and Manegement, 118, 416-422.

Little, K. W., \& McCrodden, B. J. (1989). Minimization of raw water pumping cost using MILP. Journal of Water Resources Planning and Management, 115(4), 511-522. http://dx.doi. org/10.1061/(ASCE)0733-9496(1989)115:4(511).

López-lbáñez, M., Prasad, T. D., \& Peachter, B. (2008). Ant colony optimization for optimal control of pumps in water distribution networks. Journal of Water Resources Planning and Management, 134(4), 337-346. http:// dx.doi.org/10.1061/(ASCE)0733-9496(2008)134:4(337).

McCormick, G., \& Powell, R. S. (2004). Derivation of near-optimal pump schedules for water distribution by simulated annealing. The Journal of the Operational Research Society, 55(7), 728-736. http://dx.doi.org/10.1057/palgrave.jors.2601718.

Ormsbee, L., \& Lansey, K. (1994). Optimal control of water supply pumping systems. Journal of Water Resources Planning and Management, 120(2), 237-252. http:// dx.doi.org/10.1061/(ASCE)0733-9496(1994)120:2(237).

Puleo, V., Morley, M., Freni, G., \& Savić, D. (2014). Multi-stage linear programming optimization for pump scheduling. Procedia Engineering, 70, 1378-1385. http://dx.doi. org/10.1016/j.proeng.2014.02.152.

Toledo, F. M. B., Santos, M. 0., Arenales, M. N., \& Seleghim Junior, P. S. (2008). Logística de distribuição de água em redes urbanas: racionalização energética. Pesquisa Operacional, 28(1), 75-91. http://dx.doi.org/10.1590/ S0101-74382008000100005.

Tsutiya, M. T. (2006). Redução do custo de energia elétrica em sistemas de abastecimento de água. Rio de Janeiro: Associação Brasileira de Engenharia Sanitária e Ambiental.

Ulanicki, B., Kahler, J., \& See, H. (2007). Dynamic optimization approach for solving an optimal scheduling problem in water distribution systems. Journal of Water Resources Planning and Management, 133(1), 23-32. http://dx.doi. org/10.1061/(ASCE)0733-9496(2007)133:1(23).

\section{Agradecimentos}

Esta pesquisa contou com o apoio financeiro da FAPESP (05/58059-4) e do CNPq (300713/2010-0; 304194/2011-5). 


\section{Optimization of electrical energy costs in the scheduling of catchment, storage, and distribution of water}

\section{Abstract}

The problem considered in this paper consists of the reduction of electrical energy costs necessary for the operation of hydraulic pumps, which are used to collect water from artesian wells or from a Water Treatment Station to fill water tanks located in many districts of a city. The water is then supplied by gravitational force. Because the cost of electrical energy varies throughout the day, a pump running schedule is necessary. The problem consists of determining when the pumps must be on and when there must be water transfer among tanks to ensure that the demand of each water tank be supplied, thereby minimizing the costs of electrical energy. This problem was modeled as an integer linear optimization problem, and a heuristic solution to the problem is proposed. Computational experiments show the efficiency of the heuristic and highlight how the approach can be used to analyze the impact of changes in the infrastructure of the water supply system.

\section{Keywords}

Water supply. Scheduling. Electric energy. Mixed integer linear programming. Heuristic methods. 